\title{
Fundamentals of effective activity of structural divisions of the company
}

\author{
Vladislav Kukartsev ${ }^{1,{ }^{*}}$, Valerii Kernitskii ${ }^{1}$, Evgeniya Semenova ${ }^{1}$, Olga Kuimova ${ }^{1}$ and Vladimir Khramkov ${ }^{1}$ \\ ${ }^{1}$ Reshetnev Siberian State University of Science and Technology, 31, Krasnoyarsky Rabochy Av., 660037 Krasnoyarsk, Russian \\ Federation
}

\begin{abstract}
This article is devoted to the theoretical study of the foundations of the effective operation of the company's structural divisions. It examines the general directions of development of companies and the main strategies that are most relevant for companies that produce goods in modern market conditions. Also, in this article, attention is paid to specific areas of improvement of divisions in companies, the main of which are precisely the production departments. To understand the essence of unit improvement, leadership strategies were considered. Methods and factors influencing the improvement of the activity of a subdivision of a manufacturing enterprise are analyzed. All factors are considered in the context of the enterprise from two sides, both external and internal, and diagrams are built for them for visual presentation. On the basis of these factors, directions were developed to increase the economic efficiency of activities. The final stage was considered 8 ways to improve the efficiency of enterprise management. At the end of the work, conclusions were drawn about the reasons that necessitate the improvement of units in the modern market. The purpose of this work is to study the main directions for the development of companies and the activities of their structural divisions.
\end{abstract}

\section{Introduction}

The efficiency of the functioning of any company directly depends on the efficiency of its structural divisions, the possibility of rational interaction between adjacent structural divisions and labor resources in general. Evaluation of the effectiveness of the company as a whole is based on the degree of efficiency in the implementation of the working processes of its divisions; therefore, the improvement of the company as a whole is always local in nature, affecting certain departments and corresponding processes [1-3].

The dynamically changing nature of the external environment makes it necessary for enterprises to improve their activities on an ongoing basis in order to ensure all the greater efficiency of its functioning. This requires effective technologies, working methods and timely analysis in order to be able to adapt in time to changing market conditions [4-6].

The main issue that organizations face today is effective change management. In a dynamic market, organizations must be able to quickly adapt to changes in the external environment in order to survive. Often, the complexity and speed of change test the ability of managers and workers to adapt to a situation. This adaptation should consider not only external opportunities and emerging prospects, but also internal capabilities and the quality of the processes, because the growth of activities and a large market share do not say anything about the amount of profit that the company has at the end of the reporting year [7-9].

Changes in the company occur on the basis of management decisions that change one or more internal variables in the organization's goals, structure, tasks, technology and talent. In making such decisions, management must be proactive or reactive, i.e. or to be active on its own, or to respond to the demands of the situation. To be a market leader, you need to be among the first to notice trends and change, but in order to simply stay in the market and have good revenue indicators, it is enough to simply react to changes in time. If the management does not conduct adequate analysis and does not strive to improve its own activities, then such a company will soon lose in the competition based on price, quality or other factors that are important to consumers [10-12].

Because of the complexities of the state of some of the innovating and changing variables, the interdependencies of these variables, and the responses to innovation, effective change management is one of the most difficult but fundamental challenges for managers. Managers, as well as line personnel, must constantly notice and implement changes in the organization. There is synergy here - managers are focused more on the external sphere of the company's work, while the staff is focused on internal processes, because who else but they know better all the subtleties and nuances that can be changed for the better. Requirements for changes can come both from within the company in the form of the

\footnotetext{
* Corresponding author: vlad_saa_2000@mail.ru
} 
needs and expectations of employees, and from the outside in the form of increasing competition, technological innovation and other factors [13-15].

\section{Materials and Methods}

Currently, there are many ways to improve the efficiency of the company $[9,10]$, each of which is aimed either at the head himself, or at any element of management activity. Work on improving work can begin with any element, improvement of which is most relevant for the organization. Relevance is expressed primarily by the degree of influence on the company's revenue and final profit. Therefore, the first and most important direction of improving the company's activities is to improve the functioning of its structural divisions, engaged in the main production:

A thorough diagnosis of organizational problems is absolutely essential as a starting point for carrying out planned organizational changes. In almost any organization, you can find patterns of behavior or procedures that have existed for a long time without changes, and no one can explain why and why this happens or find any meaning in these actions.

Diagnostics of changes in the organization should show the characteristic features of enterprise management and directions for its improvement, considering the stage of the life cycle, identify prospects and key competencies. Diagnostics should make it possible to formulate goals and key tasks, the consistent achievement of which will allow the organization to move in the desired direction. These goals may include: increasing profits; increasing production efficiency; the growth of the enterprise and the scale of its activities; building a business reputation; certain technological superiority and reduced risk of bankruptcy. The most common ways to improve the work of an organization, are [6]:

- improvement of the activities of the main production departments, which includes the improvement of both the main production processes and auxiliary ones;

- improvement of the management structure, its maximum simplification, decentralization of most functions, determination of the powers of managers, considering their qualifications and personal qualities;

- elaboration of a strategy for the development of the organization based on an analysis of its strengths and weaknesses, development of the philosophy and policy of the organization, covering all its functional areas;

- development of an organization's information system that ensures effective communication between employees and departments;

- development of a decision-making system, rules and management procedures, incentive systems;

- a system of continuous professional development of employees on the basis of training, retraining, development of initiative, creativity.

The diversity of the set of conditions in which companies operate, it is impossible to give a universal answer about how they should develop, because even for companies of the same size, operating in the same market, they can adhere to completely different goals, work for different target segments, and these differences are enough. The final development of their activities is radically different for them. In a dynamic environment, companies must independently decide on the choice of ways to improve management efficiency, depending on the specifics of the activity and the characteristics of the already established management system.

The extensive theoretical and methodological base of modern management allows one to constructively determine the directions of analysis and improvement of both the management system as a whole and its individual elements. At the same time, it is important for any leader to realize that the greatest efficiency of management activities will be achieved if various methods are used in a complex, focusing at the same time on the goals and strategies of the enterprise's development.

Only management that is adequate to market conditions can ensure the efficient use of resources (material, financial, labor, etc.) and solve the problem associated with increasing the competitiveness of the enterprise. This is a key factor in the success and prosperity of the enterprise [13].

A consistent analysis of the theoretical and methodological aspects of organization management allows us to form the following conclusion: management is defined as an integration process through which professionally trained specialists form organizations and manage them by setting goals and developing ways to achieve them.

The variety of purposes, goals and objectives of organizations determine their special differences; therefore, their management requires special knowledge and art, methods and techniques that consider the characteristic features of the organization. Management of the organization should be built considering these specific features, changing under the influence of external circumstances and as a result of the growth and development of the organization.

To ensure its long-term survival, a company must first of all produce a product that will consistently find buyers. This means that the product should be, firstly, interesting to the buyer so much that he is ready to give money for it. And, secondly, the buyer is interested in more than a similar product in terms of consumer qualities produced by other companies.

If a product has these two properties, then the product is said to have a competitive advantage. Consequently, an enterprise can conduct its production activities successfully only when their product has a competitive advantage.

Consideration of the creation and retention of competitive advantages involves the analysis of relations and, accordingly, the interaction of three subjects of the market environment [2]:

- the company-object of the analysis;

- its competitors who can sell a similar product that can satisfy the same need;

- the buyer. 
The main thing in this market triangle is the buyer. Therefore, the competitive advantages of a product should consider those values that correspond to a specific consumer. Competitive advantage does not necessarily arise from product comparisons between different companies. It may be that there are no competitors on the market, but the product is not for sale. There is only one reason for this - the price. Economic theory says that a market exists when there are people willing to buy a product at a certain price. If the price set by the company does not correspond to the idea of an adequate consumer price, then there will be no sales. Therefore, the main thing to pay attention to is the cost of production activities, since the price makes the product more or less valuable in the eyes of the client.

Thus, the price is the main competitive advantage in the eyes of the buyer and very often he buys it precisely because it is cheaper than others. In this case, we can say that the company's production process is its competitive advantage, since its consequence is the characteristic of the product that is important to the consumer. Such purchases can occur even if the product has no consumer utility to the customer.

The second type of competitive advantage is product differentiation, i.e. how it differs from peers on the market. Differentiation is not necessarily related to the consumer qualities of the product (reliability, ease of use, good functional characteristics, etc.). It can be achieved due to such characteristics that have nothing to do with its consumer properties, for example, due to the brand, brand, and recognition [12].

Also, an enterprise can create competitive advantages in a product due to its market position. This is achieved by securing the buyer or, in other words, by monopolizing a part of the market, when the product is significantly different in some way from competitors. An example can be any multilateral market, when a group of users of a certain product creates a kind of ecosystem, and in order to have a relationship with them, other people are forced to also start using such a product. This, for example, can be any social network.

There are three strategies for creating competitive advantage that a company can focus on, and these are discussed in Table 1 [4].

All these strategies have significant differences among themselves and provide for the implementation of actions that are different from each other, so the company needs to determine which strategy to follow and work out the appropriate measures to gain a competitive advantage.

Just as the chosen strategy influences the choice of the vector of the company's development, so the factors influence the direction of the division's development. There are internal and external factors. External factors practically do not depend on the activities of the enterprise or unit itself and they include [8]:

- Business conditions.

- Demographic changes.

- Social changes.

- The level of demand and supply for labor.
- The level of prices for raw materials and energy resources.

- Access to finance.

Internal factors, on the contrary, affect the efficiency of the enterprise and completely depend on the management decisions taken. Internal factors are divided into [8]:

- Personnel management system.

- Application of technologies and know - how.

- Range of products.

- Price policy.

- Company image.

- Availability of capital and resources.

- Profit distribution system.

Table 1. Leadership strategies.

\begin{tabular}{|c|c|}
\hline Strategy & Direction of the company \\
\hline Price Leadership & $\begin{array}{l}\text { Focused on its own costs. The goal } \\
\text { is to minimize them as much as } \\
\text { possible. Key sources of cost } \\
\text { benefit: hands-on experience in } \\
\text { relevant activities, economies of } \\
\text { scale, reduced fixed costs, } \\
\text { development of logistics, } \\
\text { convenient geographic location. }\end{array}$ \\
\hline Product differentiation & $\begin{array}{l}\text { Endow your own product with } \\
\text { distinctive features that can be } \\
\text { relevant to the consumer and for } \\
\text { which he is willing to pay. The } \\
\text { main thing is to change the market, } \\
\text { to shift the focus from some } \\
\text { characteristics to others, where the } \\
\text { company is the only one. The sales } \\
\text { volume is growing due to the } \\
\text { growth of the sold products in } \\
\text { physical terms. To do this, you } \\
\text { need to determine: who makes the } \\
\text { decision to make a purchase, } \\
\text { determine the consumer's criterion } \\
\text { grid, how he chooses a product, } \\
\text { find out where he gets information } \\
\text { about the product from. }\end{array}$ \\
\hline $\begin{array}{c}\text { Spot satisfaction of the } \\
\text { needs of the target } \\
\text { segment }\end{array}$ & $\begin{array}{l}\text { Create a product exclusively for } \\
\text { the needs of a certain segment (for } \\
\text { example, a phone with large } \\
\text { buttons for the visually impaired). } \\
\text { The goal of a strategy is to satisfy } \\
\text { the unusual need of a specific } \\
\text { group of people. This ensures that } \\
\text { there is no competitive influence } \\
\text { from similar products. With this } \\
\text { approach, to attract a client, you } \\
\text { can additionally use both the first } \\
\text { and the second strategy. }\end{array}$ \\
\hline
\end{tabular}

A more detailed and expanded system of factors affecting the efficiency of the enterprise and the decisions made on the development of structural units is presented in Figure 1 for external factors, and in Figure 2 - for internal [6]. 


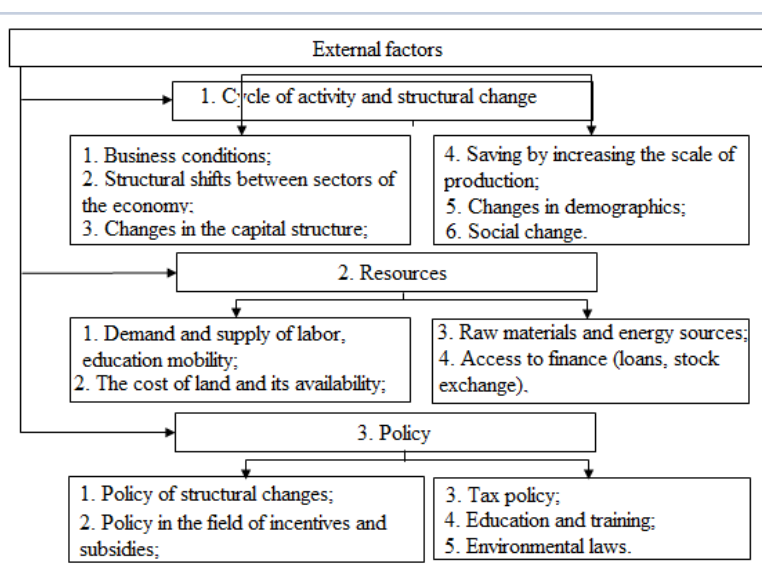

Fig. 1. External factors affecting the activities of enterprises.

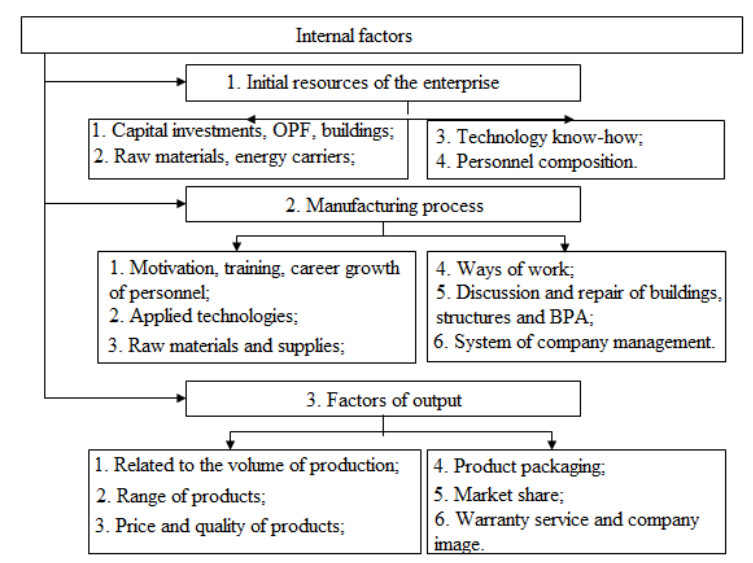

Fig. 2. Internal factors affecting the activities of enterprises.

The above factors are the basis for the development of directions to increase the economic efficiency of enterprises. These areas include [4]:

- Increase in production volumes, assortment and quality of products.

- Increasing labor productivity.

- Reduction of costs and expenses.

- Expansion of sales markets.

- Improving the efficiency of using fixed assets.

- Inventory optimization.

- Development of relationships with suppliers.

- Introduction of the latest technologies.

- The use of modern technologies for managing production processes using appropriate programs.

\section{Results and Discussion}

It is also worth noting that in the modern conditions of a market economy, the basis for the successful operation of any company in our country is to improve management efficiency. There are many ways to improve management efficiency [14-17]. Their objects can be a leader, personal and professional qualities of managers, and elements of management activities. Work in the field of improving the efficiency of the organization's management can be started from any of its elements, that is, from the most relevant for the enterprise. It is only necessary to consider the relationship of the elements of the control system with each other. Ways to improve the efficiency of enterprise management are conventionally divided into eight groups [1,7]:

- improvement of the enterprise management structure is aimed at its maximum simplification, decentralization, distribution and determination of the powers of management employees, taking into account the requirements for qualifications and personal qualities;

- development of an enterprise development strategy based on an analysis of its activities, assessment of strengths and weaknesses, development of a philosophy, concept, mission and policy of the enterprise;

- development and implementation of the company's information system, which should ensure effective communication between employees and departments;

- introduction of a system for making and developing management decisions, rules and management procedures, incentive and motivation systems;

- development and implementation of a system of continuous professional development of employees based on training, retraining, development of initiative, creativity;

- development of an algorithm, regulations or systems for the selection, training, certification or assessment of the company's management personnel, career planning for managers, the use of a leadership style that is adequate to internal and external factors affecting the organization;

- the use of the most effective methods of personnel selection, its assessment, the formation of a workable, compatible composition of employees, the creation of the most favorable socio-psychological climate;

- work to create a culture of the organization, the development of shared values, recognized and approved by employees.

Thus, based on the study of the theoretical literature, the following logical conclusions can be drawn:

- the economic efficiency of a commercial organization is defined as the effectiveness of its functioning. Currently, there are at least three fundamental approaches to the concept and assessment of economic efficiency;

- analysis of the economic efficiency of the organization's activities, involves a comprehensive study of all aspects of the functioning of the research object using statistical, financial, economic and factor analysis methods;

- the result of assessing the effectiveness of the enterprise, in any case, is the search and identification of problems and weaknesses, which must subsequently be eliminated.

\section{Conclusions}

There are many reasons, internal and external ones that necessitate the improvement of divisions in today's market:

- The level of indicators of most processes tends to decrease over time, if not maintained. This means that just to maintain the current standards, it is necessary to 
carry out a certain amount of work on the maintenance of production. If, in addition to this, the company wants to improve and renew itself; this will require not only maintenance, but also additional efforts.

- If some organization does not improve, then competitors are actively engaged in it. Therefore, the analysis and improvement of performance should be carried out by management on an ongoing basis.

- Modern consumers are becoming more and more demanding. The level of supplies and their quality are increasing all the time. This, in turn, leads to a rapid rise in consumer expectations. It is not always possible to exceed expectations, which is considered an ideal situation. You need to at least comply with them. If this is not done, then the company is guaranteed to lose a client [11].

\section{References}

1. A.V. Vyalov, Lean production: a tutorial (Komsomolsk-on-Amur, FGBOU VPO "KnAGTU", 2017)

2. A.A. Boyko, V.V. Kukartsev, E.S. Smolina, V.S. Tynchenko, Y.I. Shamlitskiy, N.V. Fedorova, Jour. of Phys.: Conf. Ser. 1353, 012124 (2019)

3. T.Yu. Grubich, Paradigms of modern sci. 2, 79 (2017)

4. N.A. Gukasyan, Management of the enterprise. Just about the complicated (St. Petersburg, BHV, 2020)

5. V.Zh. Dubrovsky, Economy of the company (Yekaterinburg, Ural State Publishing House. econom. University, 2019)

6. A.V. Kukartsev, A.A. Boyko, V.V. Kukartsev, V.S. Tynchenko, V.V. Bukhtoyarov, S.V. Tynchenko, IOP Conf. Ser.: Mat. Sci. and Eng. 537, 042009 (2019)

7. A.V. Ilchenko, Ac. prob. of econ. Sci.: mat. of the III Int. sci. conf. 1, 127 (2018)

8. I. Masaaki, The way to reduce costs and improve quality (Moscow, Alpina Publisher, 2017)

9. V.D. Markova, S.A. Kuznetsova, Strategic management: concepts, concepts, decisionmaking tools: a reference guide (Moscow, INFRA-M, 2019)

10. G. Mintzberg, Strategic safari: an excursion through the wilds of strategic management (Moscow, Alpina Publisher, 2019)

11. V.S. Tynchenko, V.V. Tynchenko, V.V. Bukhtoyarov, V.V. Kukartsev, V.A. Kukartsev, D.V. Eremeev, IOP Conf. Ser.: Mat. Sci. and Eng. 537, 042010 (2019)

12. N.F. Revenko, Organization of production and management at machine-building enterprises (Moscow: Higher school, 2017)

13. E.A. Chzhan, V.S. Tynchenko, V.V. Kukartsev, N.V. Fedorova, A.S. Yamshchikov, D.A. Krivov, IOP Conf. Ser.: Earth and Env. Sci. 315, 022106 (2019)

14. E. Volkova, E3S Web of Conf. 244, 03023 (2021)
15. N. Havlovska, O. Illiashenko, O. Konoplina, I. Shevchuk, A. Hlynska, V. Prytys, TEM J. 9, 1053 (2020).

16. O.V. Demyanova, A. Kireeva-Karimova, L.M. Zabirova, Jour. of Eng. and App. Sci. 12, 4952 (2017) 